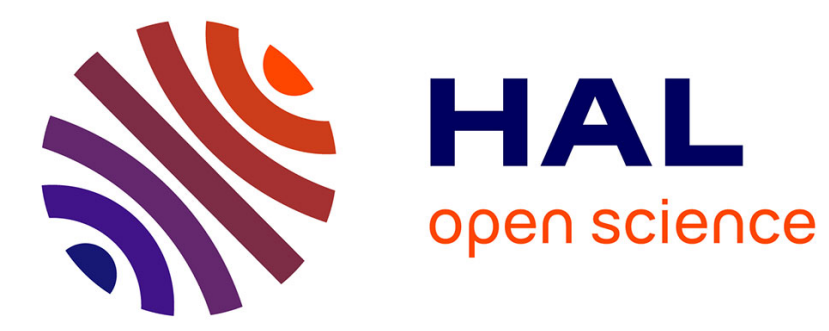

\title{
Optimal Planning of Electric Power Systems
}

Islam Abdin, Enrico Zio

\section{To cite this version:}

Islam Abdin, Enrico Zio. Optimal Planning of Electric Power Systems. Optimization in Large Scale Problems, 2019, Springer Optimization and Its Applications, 10.1007/978-3-030-28565-4_10 . hal02428593

\section{HAL Id: hal-02428593 \\ https://hal.science/hal-02428593}

Submitted on 6 Jan 2020

HAL is a multi-disciplinary open access archive for the deposit and dissemination of scientific research documents, whether they are published or not. The documents may come from teaching and research institutions in France or abroad, or from public or private research centers.
L'archive ouverte pluridisciplinaire HAL, est destinée au dépôt et à la diffusion de documents scientifiques de niveau recherche, publiés ou non, émanant des établissements d'enseignement et de recherche français ou étrangers, des laboratoires publics ou privés. 


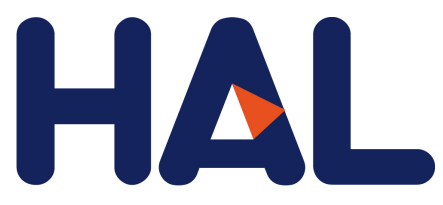

archives-ouvertes

\section{Optimal Planning of Electric Power Systems}

Islam Abdin, E. Zio

\section{To cite this version:}

Islam Abdin, E. Zio. Optimal Planning of Electric Power Systems. Optimization in Large Scale Problems, 2019, 10.1007/978-3-030-28565-4_10. hal-02428593

\section{HAL Id: hal-02428593 \\ https://hal.archives-ouvertes.fr/hal-02428593}

Submitted on 6 Jan 2020

HAL is a multi-disciplinary open access archive for the deposit and dissemination of scientific research documents, whether they are published or not. The documents may come from teaching and research institutions in France or abroad, or from public or private research centers.
L'archive ouverte pluridisciplinaire HAL, est destinée au dépôt et à la diffusion de documents scientifiques de niveau recherche, publiés ou non, émanant des établissements d'enseignement et de recherche français ou étrangers, des laboratoires publics ou privés. 


\title{
Optimal Planning of Electric Power Systems
}

\begin{abstract}
Electric power systems provide an essential service to any modern 4 society. They are inherently large- scale dynamic systems with a high degree of 5 spatio-temporal complexity. Their reliability and security of supply are central 6 considerations in any regional or global energy-related policy. Methods for power 7 systems planning have typically ensured key operational reliability aspects under 8 normal operating conditions and in response to anticipated demand variability, 9 uncertainty and supply disruptions, e.g. due to errors in load forecasts and to 10 unexpected generation units outages. Solutions have been commonly built on 11 capacity adequacy and operating reserves requirements, among others. However, 12 recent objectives for environmental sustainability and the threats of climate change 13 are challenging the reliability requirements of power systems in various new ways 14 and necessitate adapted planning methods.

The present chapter describes some of the issues related to the development of 16 the integrated techno-economic modeling and robust optimization framework that 17 is needed today for power systems planning adapted. Such planning framework 18 should cope with the new context by addressing the challenges associated with 19 the sustainability targets of future power systems, and most notably ensuring 20 operational flexibility against the variability of renewable energy sources, ensuring 21 resilience against extreme weather events and ensuring robustness against the 22 uncertainties inherent in both the electric power supply and system load.

\section{F. Abdin}

Laboratoire Genie Industriel, CentraleSupelec, Universite Paris-Saclay, Gif-sur-Yvette, France

E. Zio $(\bowtie)$

AQ1 Chair Systems Science and the Energy Challenge, Fondation Electricie de France (EDF), CentraleSupelec, Universite Paris-Saclay, Gif-sur-Yvette, France

Mines ParisTech, PSL Research University, Sophia Antipolis, France

Department of Energy, Politecnico di Milano, Milan, Italy

Eminent Scholar, Department of Nuclear Energy, Kyung Hee University, Seoul, South Korea e-mail: enrico.zio@ mines-paristech.fr 
This chapter presents the context by summarizing the main sustainability drivers 24 for the current (and future) power systems planning and operation. These well- 25 known sustainability targets have become a worldwide imperative in all sectors 26 of economic activity, and are embedded within almost any regulatory or policy 27 dialogue. We will, then, review the particular transformation undergoing in the 28 electric power sector planning, not only driven by the sustainability goals, but also 29 by the more general technological and/or regulatory advancements. The main power 30 systems planning related challenges are detailed, along with a thorough review 31 of previous research works and research gaps. Then, key research questions and 32 ensuing objectives are formulated.

\section{Sustainability of Future Electric Power Systems}

The electric power industry is at the same time a major contributor to climate change 35 and a sector that will be deeply disturbed by the effects of climate change. The role 36 of the power sector towards climate change stems from the fact that it is the largest 37 contributor to global greenhouse gas (GHG) emissions. From 2000 to 2010, the 38 increase in the power sector emissions outpaced the increase in overall emissions 39 by around $1 \%$ per year [1]. In 2018, global energy-related $\mathrm{CO}_{2}$ emissions rose $1.7 \% \quad 40$ to a historic high of $33.1 \mathrm{Gt} \mathrm{CO}_{2}$. The power sector accounted for nearly two- 41 thirds of this emissions growth [2]. To reduce emissions to levels equivalent with 42 the internationally agreed goal of keeping the temperature increase below $2{ }^{\circ} \mathrm{C}$ of 43 that of pre-industrial levels, the share of low-carbon electricity generation will need 44 to triple or quadruple by 2050 [2].

At the same time, it is expected that over the coming decades the power sector 46 will be significantly disturbed by climate change impacts. For example, power 47 plants, especially those in coastal areas, will be affected by extreme weather events 48 and rising sea levels. Electricity grids will be impacted by storms, and the rise in 49 global temperature may affect electricity generation including thermal and hydro- 50 electric stations in many locations. And while the industry may have options for 51 adapting to climatic changes, significant costs are likely to be incurred [3]. Several 52 actions are, therefore, urgently needed if the reliability and sustainability targets for 53 the power sector are to be achieved.

\subsection{Greenhouse Gas Emissions}

Controlling GHG emissions ultimately requires "de-carbonizing" the power sector, 56 both by reducing the high demand for energy and by supplying power that generates 57 much less GHG. A clear path for de-carbonizing power production is through what 58 the Intergovernmental Panel on Climate Change (IPCC) describes as a fundamental 59 shift in global investment from fossil fuel to renewable energy [1]. Renewable 60 


\section{Author's Proof}

Optimal Planning of Electric Power Systems

energy sources have significant potential for reducing GHG emissions and are 61 becoming mainstream investment choices as they are becoming more competitive. 62 In 2012, they accounted for just over half of the new electricity-generating capacity 63 investments globally, while electricity generation from renewable sources increased 64 by over $7 \%$ in 2018 alone [2]. Yet only a small fraction of renewable potential 65 has been exploited so far; estimates suggest that in different regions of the world, 66 renewable energy sources can produce more than 2.6 times the energy demand [1]. 67 Another path for supporting the reduction of GHG is placing more stringent limits 68 on carbon emissions for existing or new thermal plants. A clear example is the use 69 of carbon capture and storage (CCS) technology already imposed in many regions. 70

\subsection{Climate Change}

Ensuring the resilience of the power system against the adverse effects of climate 72 change is another key element for ensuring the sustainability and reliability of 73 power supply. The past decade has seen a rising frequency in weather-related natural 74 disasters. Damage and loss associated with these extreme events resulted in millions 75 of victims and billions of dollars in losses. There are various ways in which climate 76 change affects the power sector [4]:

- Extreme weather events such as storms, floods and extreme temperatures can 78 impact the power production and delivery, causing supply disruptions and 79 infrastructure damage.

- The reduction in water availability can constrain hydropower as well as the 81 operation of the thermal power plants (fossil fuel and nuclear), which require 82 water for cooling.

- Unusual seasonal temperatures can impact the electricity demand patterns due 84 to the increased need for cooling during summer heat waves, or the increased 85 demand for heating in excessively cold winters.

Although thermal power plants are designed to operate under diverse climatic 87 conditions, they will be particularly affected by the decreasing efficiency of thermal 88 conversion as a result of rising ambient temperatures. In addition, in many regions, 89 decreasing volumes of water available for cooling and increasing water temperatures 90 could lead to reduced power operations, operations at reduced capacity or even 91 temporary shutdowns [5]. The rising temperatures also create challenges for meeting 92 river temperature regulations. For example, in 2009, the French power system at one 93 time lost one third of its nuclear capacity, to respect thermal discharge limits [4]. $\quad 94$

Within this context, it is clear that current power system planning efforts must be 95 able to account for these future challenges or, otherwise, they run the risk of leading 96 to inadequate and unreliable investments. 


\section{Electric Power Systems Planning}

Power system planning is an important techno-economic problem, which has 99 been addressed extensively both by the sector stakeholders and by academics. 100 Research on power system planning is carried out by governments and power system 101 operators for future system-wide expansion, and for deciding on optimal policies 102 and regulations. It is also carried out within privately owned power utilities in 103 countries which have liberalized the energy sector, to plan for future investments. 104

Electric power systems planning can be divided into two main problems: 105 generation expansion planning (GEP) and network expansion planning (NEP). Both 106 are typically formulated as optimization problems, seeking to determine the optimal 107 technology mix, location and construction time of new generation units, as well as 108 the optimal size and location of the power lines. Albeit being highly intertwined, 109 the complexity and scale of each problem has led research work to often focus on 110 addressing each of them separately [6].

The present work focuses on the modeling of the GEP problem and the 112 optimization of its solution, as it is considered most critically affected by the future 113 context, both from the economic (costs) and technical (service provision) aspects. 114 In literature, GEP modeling in a centralized planning context can be traced back to 115 the seminal paper [7]. With the power sector being constantly subjected to changes 116 driven by economical, technical, technological and environmental issues, the body 117 of GEP literature has persistently expanded to accommodate the new requirements, 118 through a variety of modeling and solution methods. Some of the developments 119 include: improvements in the details considered, such as reserve requirements 120 $[8,9]$, reliability and maintenance [8, 10-12], policy developments such as the 121 restructuring of the power sector and the introduction of competition $[10,13-122$ 15], $\mathrm{CO}_{2}$ mitigation solutions [16, 17], renewable energy resources integration and 123 support schemes [15,18-21], uncertainty and stochasticity in generation production 124 and demand [10, 19, 22-25], demand side management (DSM) [26, 27], and smart- 125 grids [28], among others. Reviews of the GEP problem can be found in [6, 29, 30], 126 and a comprehensive recent review in [31].

In particular, as noted in the previous section, the need to combat climate through 128 the decarbonization of the sector, as well as the advancements in the information and 129 communication technology (ICT) has paved the way to fundamental transformations 130 in both the electricity supply and demand of electricity). On the supply side: 131

- There is an increased shift from large synchronous generators to light-weight 132 decentralized ones.

- There is an increased penetration of intermittent renewable energy sources 134 (IRES), for which the investments are getting cheaper and the remuneration 135 programs are becoming more attractive. 136

- There is an increased threat of power disruption due to extreme weather events. ${ }^{137}$ 


\section{Author's Proof}

Optimal Planning of Electric Power Systems

On the demand side:

- There is a growing number of distributed variable generation resources, in the 139 form of electric vehicles, electric solar production roof-tops, micro-grids, energy 140 storage systems, among others.

- There is a usage shift of the demand from being passive (pure consumers) to 142 being active (both consumers and small-scale producers, i.e. "prosumers"). 143

This transformation is driven by technological advancement (e.g. the devel- 144 opments in the communication and control systems, affordable investments in 145 renewable technologies), as well as by global energy policies with the aim of moving 146 towards decentralized power generation and bi-directional power flow.

These developments are posing a number of pressing challenges that need to 148 be adequately and methodologically addressed within the power system planning 149 framework.

\section{Electric Power Systems Planning Challenges}

Traditional GEP models, based on step-wise load duration curves or other non152 chronological approximations, have for long been appropriate for power systems 153 planning, especially in systems dominated by dispatchable hydro-thermal units and 154 with the primary concern of generation adequacy (e.g. [40-42]). These models 155 have the main advantage of being computationally cheap, and therefore large sized 156 systems and long-term planning horizons up to several decades can be easily 157 optimized. However, when it comes to planning for system flexibility under IRES 158 penetration, recent studies have started to show the importance of integrating the 159 UC short-term constraints within the long-term planning model [9, 43-50]. 160

Study [43] considers a combined GEP-UC model for planning over a single 161 year, reduced to 4 weeks with chronological hourly representation, each week 162 representing a season. In [9] a detailed formulation of the combined GEP-UC 163 problem is provided and employed for the analysis of the Greek power system, 164 under several scenarios of carbon emission pricing, emission caps, and IRES 165 penetration targets. A multi-annual planning horizon is considered, where the 166 year is approximated to 12 days, each one representing a month. The results 167 reveal the correlation between significant IRES penetration with large amounts 168 of natural gas production, which offers more flexibility to the power system. 169 Similarly, in [44] a combined model for multi-annual planning is proposed and 170 a clustering representation of the units in integer variables is presented. Several 171 planning horizons are considered, where annual demand is reduced to a number 172 of representative weeks selected in an ad-hoc manner. The comparison on the case 173 study shows that when short-term constraints are considered, higher investments are 174 driven to flexible peaking plants. In [45], a soft-linking between long-term and short- 175 term models is implemented. The framework is to solve a long-term low resolution 176 model to obtain a generation portfolio under a single IRES penetration scenario 177 
and to embed this portfolio in a short-term chronological model, which is solved 178 multiple times with increasing level of technical constraints. It considers a case 179 study for a single year and uses the number of units start-ups as a proxy for flexibility 180 evaluation. A very similar approach is implemented in [46], but also varying the 181 IRES penetration level. The impact of including several short-term constraints (most 182 notably: startups/shutdowns, minimum stable load, ramping rates and operating 183 reserves) is analyzed for a future planning year. Study [47] solves a planning model 184 based on a basic screening curve method and proposes a perturbation algorithm with 185 embedded short-term constraints to improve the plans obtained. A single future year 186 is considered under different IRES penetration scenarios. A brief comparison of 187 the results obtained pre- and post-implementation of the perturbation algorithm, in 188 terms of the installed capacity, is discussed. It shows that considering the short-term 189 constraints results in less installation of base load capacity compared to mid- and 190 peak-load ones. Finally, studies [48, 49] compare the results of a fully integrated 191 model to those of a traditional planning only model. The former work considers 192 only a single future planning year, whereas the latter considers a multi-annual 193 planning horizon of 10 years, where each year is approximated to 4 days in an 194 ad-hoc manner. The comparison is based on the costs and emission levels resulting 195 from both models, and shows that neglecting these constraints underestimates both 196 attributes.

\subsection{Operational Flexibility}

Properly quantifying operational flexibility is critical for evaluating the overall 199 system reliability. Whereas reliability relates to the fact that sufficient firm-capacity 200 is available at each time period to satisfy the system load, as measured by typical 201 metrics, such as loss of load expectation (LOLE) and expected energy not supplied 202 (EENS), operational flexibility considers how a specific operational state of the 203 system at a given period would contribute to (or hinder) its ability to deploy 204 its resources for accommodating variations in subsequent periods: for this, no 205 time period can be assessed in isolation of the others, nor without de- tailed 206 knowledge of the exact system state and technical characteristics at the given 207 period. Therefore, metrics to describe operational flexibility have been proposed 208 in the literature, varying in the degree of complexity and in the data required for 209 their estimation. The work in [51] proposes a probabilistic metric that takes into 210 account key technical characteristics of the generation units and aggregates them 211 for a system-level assessment. In [52], a number of interdependent metrics are 212 defined for individual generation units to assess their available flexibility in real 213 time. Study [53] proposes two flexibility indices to provide an offline estimation 214 of the flexibility level of power systems. The first metric is obtained by analyzing 215 adjustable space of generators, whereas the second assesses the flexibility level 216 of a system by its capability for accommodating wind. Finally, [54] proposes a 217 metric which additionally considers the impacts of the transmission network on the 218 flexibility levels. 


\section{Author's Proof}

Optimal Planning of Electric Power Systems

\subsubsection{Research Gap}

As shown, most of the studies reviewed argue for the benefit of including the 221 short-term unit-commitment constraints within the long-term planning framework, 222 especially in terms of answering to the flexibility requirements under increased 223 IRES penetration, by analyzing the differences in capacity installation, production 224 profile, emission and curtailment levels, system costs, or a combination of these. 225 Those studies, however, do not resolve to using quantitative flexibility metrics to 226 formally assess and compare the benefits of their proposed approaches. On the 227 other hand, studies that have proposed quantitative flexibility metrics have often 228 considered existing systems for the application and do not integrate those methods 229 within the expansion planning problem itself. Furthermore, since the resulting 230 expansion problem with unit-commitment constraints is computationally intensive, 231 each study has resorted to a different combination of horizons reduction or ad-hoc 232 approximation, neglecting to address the bias that this can impose on the results.

\subsection{Resilience}

Increasingly frequent and extreme weather events, such as heat waves, droughts, 235 floods and storms, significantly affect the operational status of power systems. 236 Evidence of power generation disruptions due to such events highlights the fragility 237 of the existing systems and the need of considering resilience within the planning of 238 future power systems [55].

Particularly, heat waves are among the most worrying weather extremes, due 240 to the expected increase in their frequency and severity in the twenty-first century 241 [56, 57]. For example, France was particularly impacted by the 2003 summer heat 242 wave, which caused an excess of about 15,000 deaths from 4th to 18th August 243 directly attributable to the heat [58]. By combining peaks of extreme temperature 244 and severe soil and hydrological droughts, this event also affected significantly the 245 energy production sector (mainly because of the cooling process of thermal power 246 plants). These last years, numerous regions of the world experienced severe heat 247 waves with comparable effects: Russia in 2010, Texas in 2011, Australia in 2012, 248 India and Southern Pakistan in 2015. Therefore, it is of great importance to design 249 the ability of the energy systems for coping with future heat wave events. 250

Among the research that studied the impacts of extreme weather events on 251 power systems, [59] presents a multi-objective optimization of distributed power 252 generation systems considering extreme wind and lightning events [60]. Proposes 253 a probabilistic methodology to assess the resilience degradation of transmission 254 networks subject to extreme wind events. In [61], an extreme weather stochastic 255 model is applied to a realistic cascading failure simulator of power grids, accounting 256 for the operating conditions that a repair crew may encounter during an extreme 257 weather event. The impacts of water availability on the generation capacity expan- 258 sion planning is investigated in [62] and the electricity sector growth is compared 259 
under different scenarios of water rights [63]. Proposes an integrated electricity 260 and natural gas planning model taking into consideration the power grid resilience 261 against storms, earthquakes and floods [64]. Studies the potential impacts of heat 262 waves on power grid operation, by quantifying the capacity of thermal power plants 263 as a function of ambient temperature.

\subsubsection{Research Gap}

Whereas most of those studies focus on evaluating the impact of extreme weather 266 threats on the operation of power systems, there exist very few studies that 267 incorporate resilience within the power system planning problem itself. Moreover, 268 no study explicitly considers flexibility and resilience within a unified planning and 269 assessment framework.

\subsection{Uncertainties}

Accounting for the inherent uncertainties in IRES supply and system load is 272 another significant concern for ensuring reliable system performance. Two popular 273 approaches have been often applied to address the uncertainties for the GEP and UC 274 problems, separately. One is stochastic optimization (SO) [22, 24, 65-67], which 275 models uncertain parameters by means of scenarios generated from probability 276 distribution functions. This method may be suit- able if the probability functions 277 are available, which is not always the case, and especially when considering long- 278 term uncertainties such as in a GEP problem. Moreover, SO does not guarantee the 279 feasibility of the solution for all possible uncertainty realizations, which is a sig- 280 nificant limitation in addressing the operational flexibility issue. The other popular 281 approach is robust optimization (RO) [68], which models uncertain parameters by 282 means of distribution-free bounded intervals. RO is attractive in that it avoids the 283 above-mentioned limitations of SO, but, it has been often criticized for resulting 284 in over-conservative solutions and for being computationally intensive. State-of- 285 the art RO methods deal with these problems by introducing an uncertainty budget 286 parameter to control the conservatism of the solution and by resorting to efficient 287 solution methods (such as Column and Constraint Generation (CCG) [69] or affine 288 simplification of the recourse action [70]) to accelerate the solution.

\subsubsection{Research Gap}

Some research works have focused on RO-based approaches to handle uncertainties 291 and address operational flexibility in power systems planning and operation. In 292 [71], a two- stage adaptive RO model is proposed for long term generation and 293 transmission expansion under generator output uncertainties but with no explicit 294 


\section{Author's Proof}

Optimal Planning of Electric Power Systems

consideration of the ramping requirements. Ramping was considered in [72] for 295 power system planning but only through an approximated hourly load ramping 296 uncertainty that is based on average net-load levels. Detailed ramping constraints 297 were considered in robust unit commitment models such as in [73-76], but 298 without considering the impact on power systems planning. Moreover, [75] has 299 demonstrated how the two-stage robust UC model can lead to infeasibility in the 300 dispatch problem when the generation ramping capability is limited. This showed 301 the importance of considering non-anticipativity constraints in power systems 302 operations within a multistage robust optimization. Yet, these results were not 303 extended to investigate their impact on the power systems investment decisions. $\quad 304$

\section{Conclusions}

Planning power systems for providing secure and reliable electricity to users is key 306 in any energy strategy. This is being challenged by several recent developments, 307 most notably, the increased penetration of variable intermittent renewable energy 308 sources (IRES), which is raising concerns about the ability of future power 309 systems to effectively respond to the high net-load variations, a system property 310 which is referred to as operational flexibility. Moreover, climate change threats 311 and, particularly, the increased frequency and severity of extreme weather events, 312 are threatening to disrupt electric power supply and require the consideration of 313 system resilience right from the planning stage. Also, the inherent uncertainties 314 characterizing those systems must be inevitably considered.

To address the above-mentioned challenges, efforts must be devoted to devel- 316 oping efficient techno-economic modeling and robust optimization frameworks for 317 multi-period generation expansion planning considering high shares of IRES and 318 resilience against extreme weather events. The planning problem considers the 319 technology choice, size and commissioning schedule of conventional and renew- 320 able generation units under technical, economic, environmental and operational 321 constraints. Within this problem, key research objectives to be addressed are (i) 322 the proper integration and assessment of the operational flexibility needs due to the 323 increased variability from the high shares of IRES penetration, (ii) the appropriate 324 modeling and incorporation of the resilience requirements against extreme weather 325 events within the power system planning model and (iii) the representation and 326 treatment of the inherent uncertainties in the system supply and demand within this 327 planning context.

The framework will need to accommodate the fact that the economic planning 329 parameters and the technical behavior of energy generation are affected by nonlinear 330 conditions. For instance, production costs and ramping rates are nonlinear functions 331 of the variations in partial-load levels, whereas start-up costs and times are nonlinear 332 functions of the shut-down duration. These conditions become particularly relevant 333 when short-term capabilities and operational flexibility are considered in the model. 334 Then, the optimization model will need to give due count to the nonlinearities 335 


\section{Author's Proof}

in the system. Moreover, the modeling and optimization framework should be 336 applicable to multi-regional planning, accounting for the differences in weather 337 conditions across the different regions. Also, potential benefits should be studied, 338 of considering demand-side management policies, and/or different storage options 339 as operational flexibility and resilience enabling resources.

\section{Bibliography}

1. Allen M.R., Barros, V.R., Broome, J., Cramer, W., Christ, R., Church, J.A., Clarke, L., Dahe, 342 Q., Dasgupta, P., Dubash, N.K., et al.: IPCC fifth assessment synthesis report-climate change 343 2014 synthesis report. In: (2014)

2. IEA.: Global energy and CO2 status report. All Rights Reserved. (2018) 345

3. Cronin, J., Anandarajah, G., Dessens, O.: Climate change impacts on the energy system: a 346 review of trends and gaps. Clim. Chang. 151(2), 79-93 (2018) 347

4. IEA.: Making the Energy Sector more Resilient to Climate Change. Allrights Reserved. (2015) 348

5. Cambridge Institute for Sustainability Leadership.: Climate Change: Implications for the 349 Energy Sector. (2014)

6. Hemmati, R., Hooshmand, R.-A., Khodabakhshian, A.: Comprehensive review of generation 351 and transmission expansion planning. IET Gener. Transm. Distrib. 7(9), 955-964 (2013) 352

7. Masse, P., Gibrat, R.: Application of linear programming to investments in the electric power 353 industry. Manag. Sci. 3(2), 149-166 (1957) 354

8. Bakirtzis, G.A., Biskas, P.N., Chatziathanasiou, V.: Generation expansion planning by MILP 355 considering mid-term scheduling decisions. Electr. Power Syst. Res. 86, 98-112 (2012) 356

9. Koltsaklis, N.E., Georgiadis, M.C.: A multi-period, multi-regional generation expansion 357 planning model incorporating unit commitment constraints. Appl. Energy. 158, 310-331 358 (2015)

10. Hemmati, R., Hooshmand, R.-A., Khodabakhshian, A.: Reliability constrained generation 360 expansion planning with consideration of wind farms uncertainties in deregulated electricity 361 market. Energy Convers. Manag. 76, 517-526 (2013) 362

11. Dehghan, S., Amjady, N., Conejo, A.J.: Reliability-constrained robust power system expansion 363 planning. IEEE Trans. Power Syst. 31(3), 2383-2392 (2016). 8990 Bibliography 364

12. Min, X., Jinfu, C., Zhong, D.X.: Generator maintenance scheduling in the generation expansion 365 planning of interconnected power system. Transm. Distrib. Conf. Exhib. 2002: Asia Pacific. 366 IEEE/PES. 3. IEEE., 1601-1605 (2002) 367

13. Pereira, A.J.C., Saraiva, J.T.: A decision support system for generation expansion planning in 368 competitive electricity markets. Electr. Power Syst. Res. 80(7), 778-787 (2010) 369

14. Pereira, A.J.C., Saraiva, J.T.: Generation expansion planning (GEP)-A long-term approach 370 using system dynamics and genetic algorithms (GAs). Energy. 36(8), 5180-5199 (2011) 371

15. Pereira, A.J.C., Saraiva, J.T.: A long term generation expansion planning model using system 372 dynamics-case study using data from the Portuguese/Spanish generation system. Electr. Power 373 Syst. Res. 97, 41-50 (2013) 374

16. Sirikum, J., Techanitisawad, A., Kachitvichyanukul, V.: A new efficient GA-benders' decom- 375 position method: for power generation expansion planning with emission controls. IEEE Trans. 376 Power Syst. 22(3), 1092-1100 (2007) 377

17. Lu, Z., Qi, J., Wen, B., Li, X.: A dynamic model for generation expansion planning based 378 on conditional value-at-risk theory under low-carbon economy. Electr. Power Syst. Res. 141, 379 363-371 (2016) 380

18. Aghaei, J., MA Akbari, A., Roosta, M.G., Niknam, T.: Integrated renewable-conventional 381 generation expansion planning using multi-objective framework. IET Gener. Transm. Distrib. 382 6(8), 773-784 (2012) 


\section{Author's Proof}

Optimal Planning of Electric Power Systems

19. Zhan, Y., Zheng, Q.P., Wang, J., Pinson, P.: Generation expansion planning with large amounts 384 of wind power via decision-dependent stochastic programming. IEEE Trans. Power Syst. 32(4), 385 3015-3026 (2016)

20. Rajesh, K., Bhuvanesh, A., Kannan, S., Thangaraj, C.: Least cost generation expansion 387 planning with solar power plant using differential evolution algorithm. Renew. Energy. 85, 388 677-686 (2016)

21. Rajesh, K., Kannan, S., Thangaraj, C.: Least cost generation expansion planning with wind 390 power plant incorporating emission using differential evolution algorithm. Int. J. Electr. Power 391 Energy Syst. 80, 275-286 (2016)

22. Gil, E., Aravena, I., Cárdenas, R.: Generation capacity expansion planning under hydro 393 uncertainty using stochastic mixed integer programming and scenario reduction. IEEE Trans. 394 Power Syst. 30(4), 1838-1847 (2015)

23. Tekiner-Mogulkoc, H., Coit, D.W., Felder, F.A.: Mean-risk stochastic electricity generation 396 expansion planning problems with demand uncertainties considering conditional-value-at-risk 397 and maximum regret as risk measures. Int. J. Electr. Power Energy Syst. 73, 309-317 (2015) 398

24. Park, H., Baldick, R.: Stochastic generation capacity expansion planning reducing greenhouse 399 gas emissions. IEEE Trans. Power Syst. 30(2), 1026-1034 (2015) 400

25. Li, S., Coit, D.W., Felder, F.: Stochastic optimization for electric power generation expansion 401 planning with discrete climate change scenarios. In: Electr. Power Syst. Res., vol. 140, pp. 402 401-412 (2016)

26. Ghaderi, A., Moghaddam, M.P., Sheikh-El-Eslami, M.K.: Energy efficiency resource modeling 404 in generation expansion planning. Energy. 68, 529-537 (2014) 405

27. Satchwell, A., Hledik, R.: Analytical frameworks to incorporate demand response in long-term 406 resource planning. Util. Policy. 28, 73-81 (2014) 407

28. Tekiner-Mogulkoc, H., Coit, D.W., Felder, F.A.: Electric power system generation expansion 408 plans considering the impact of smart grid technologies. Int. J. Electr. Power Energy Syst. 409 42(1), 229-239 (2012)

29. Careri, F., Genesi, C., Marannino, P., Montagna, M., Rossi, S., Siviero, I.: Generation 411 expansion planning in the age of green economy. IEEE Trans. Power Syst. 26(4), 2214-2223 412 (2011)

30. Kagiannas, A.G., Askounis, D.T., Psarras, J.: Power generation planning: a survey from 414 monopoly to competition. Int. J. Electr. Power Energy Syst. 26(6), 413-421 (2004) 415

31. Sadeghi, H., Rashidinejad, M., Abdollahi, A.: A comprehensive sequential review study 416 through the generation expansion planning. Renew. Sust. Energ. Rev. 67, 1369-1394 (2017) 417

32. Kabouris, J., Kanellos, F.D.: Impacts of large-scale wind penetration on designing and 418 operation of electric power systems. IEEE Trans. Sustain. Energy. 1(2), 107-114 (2010) 419

33. Ummels, B.C., Gibescu, M., Pelgrum, E., Kling, W.L., Brand, A.J.: Impacts of wind power on 420 thermal generation unit commitment and dispatch. IEEE Trans. Energy Convers. 22(1), 44-51 421 (2007)

34. Charles Smith, J., Milligan, M.R., DeMeo, E.A., Parsons, B.: Utility wind integration and 423 operating impact state of the art. IEEE Trans. Power Syst. 22(3), 900-908 (2007) 424

35. Huber, M., Dimkova, D., Hamacher, T.: Integration of wind and solar power in Europe: 425 assessment of flexibility requirements. Energy. 69, 236-246 (2014) 426

36. Tabone, M.D., Goebel, C., Callaway, D.S.: The effect of PV siting on power system flexibility 427 needs. Sol. Energy. 139, 776-786 (2016) 428

37. Morales-España, G., Latorre, J.M., Ramos, A.: Tight and compact MILP formulation for the 429 thermal unit commitment problem. IEEE Trans. Power Syst. 28(4), 4897-4908 (2013) 430

38. Padhy, N.P.: Unit commitment-a bibliographical survey. IEEE Trans. Power Syst. 19(2), 1196- 431 1205 (2004)

39. Tuohy, A., Meibom, P., Denny, E., O’Malley, M.: Unit commitment for systems with significant 433 wind penetration. IEEE Trans. Power Syst. 24(2), 592-601 (2009) 434

40. Cheng, R., Xu, Z., Liu, P., Wang, Z., Li, Z., Jones, I.: A multi-region optimization planning 435 model for China's power sector. Appl. Energy. 137, 413-426 (2015) 
41. Koltsaklis, N.E., Dagoumas, A.S., Kopanos, G.M., Pistikopoulos, E.N., Georgiadis, M.C.: A 437 spatial multi-period long-term energy planning model: a case study of the Greek power system. 438 Appl. Energy. 115, 456-482 (2014)

42. Barteczko-Hibbert, C., Bonis, I., Binns, M., Theodoropoulos, C., Azapagic, A.: A multi-period 440 mixed-integer linear optimisation of future electricity supply considering life cycle costs and 441 environmental impacts. Appl. Energy. 133, 317-334 (2014)

43. Kirschen, D.S., Ma, J., Silva, V., Belhomme, R.: Optimizing the flexibility of a portfolio of 443 generating plants to deal with wind generation. In: Power and Energy Society General Meeting, 444 2011 IEEE. IEEE, pp. 1-7 (2011)

44. Flores-Quiroz, A., Palma-Behnke, R., Zakeri, G., Moreno, R.: A column generation approach 446 for solving generation expansion planning problems with high renewable energy penetration. 447 Electr. Power Syst. Res. 136, 232-241 (2016)

45. Deane, J.P., Chiodi, A., Gargiulo, M., GallachÓir, B.P.Ó.: Soft-linking of a power systems 449 model to an energy systems model. Energy. 42(1), 303-312 (2012) 450

46. Peerapat Vithayasrichareon, T. Lozanov, J.R., MacGill, I.: Impact of operational constraints on 451 generation portfolio planning with renewables. In: Power \& Energy Society General Meeting, 452 2015 IEEE. IEEE, pp. 1-5 (2015)

47. Belderbos, A., Delarue, E.: Accounting for flexibility in power system planning with renew- 454 ables. Int. J. Electr. Power Energy Syst. 71, 33-41 (2015) 455

48. Palmintier, B.S., Webster, M.D.: Impact of operational flexibility on electricity generation 456 planning with renewable and carbon targets. IEEE Trans. Sustain. Energy. 7(2), 672-684 457 (2016)

49. Pereira, S., Ferreira, P., Vaz, A.I.F.: Generation expansion planning with high share of 459 renewables of variable output. Appl. Energy. 190, 1275-1288 (2017) 460

50. Ma, J., Silva, V., Belhomme, R., Kirschen, D.S., Ochoa, L.F.: Evaluating and planning 461 flexibility in sustainable power systems. In: Power and Energy Society General Meeting (PES), 462 2013 IEEE. IEEE, pp. 1-11 (2013) 463

51. Lannoye, E., Flynn, D., O’Malley, M.: Evaluation of power system flexibility. IEEE Trans. 464 Power Syst. 27(2), 922-931 (2012) 465

52. Ulbig, A., Andersson, G.: Analyzing operational flexibility of electric power systems. Int. J. 466 Electr. Power Energy Syst. 72, 155-164 (2015)

53. Ma, J., Silva, V., Belhomme, R., Kirschen, D.S., Ochoa, L.F.: Exploring the use of flexibility 468 indices in low carbon power systems. In: 2012 3rd IEEE PES Innovative Smart Grid 469 Technologies Europe (ISGT Europe). IEEE, pp. 1-5 (2012) 470

54. Zhao, J., Zheng, T., Lityinov, E.: A unified framework for defining and measuring flexibility in 471 power system. IEEE Trans. Power Syst. 31(1), 339-347 (2016) 472

55. Fang, Y., Sansavini, G.: Optimizing power system investments and resilience against attacks. 473 Reliab. Eng. Syst. Saf. 159, 161-173 (2017)

56. Meehl, G.A., Tebaldi, C.: More intense, more frequent, and longer lasting heat waves in the 475 21st century. Science. 305(5686), 994-997 (2004)

57. Guerreiro, S.B., Dawson, R.J., Kilsby, C., Lewis, E., Ford, A.-i.: Future heat-waves, droughts 477 and floods in 571 European cities. Environ. Res. Lett. 13(3), 034009 (2018) 478

58. Poumadere, M., Mays, C., Le Mer, S., Blong, R.: The 2003 heat wave in France: dangerous 479 climate change here and now. Risk Anal.: Int. J. 25(6), 1483-1494 (2005) 480

59. Rocchetta, R., Li, Y., Zio, E.: Risk assessment and risk-cost optimization of distributed power 481 generation systems considering extreme weather conditions. Reliab. Eng. Syst. Saf. 136, 47-61 482 (2015)

60. Panteli, M., Pickering, C., Wilkinson, S., Dawson, R., Mancarella, P.: Power system resilience 484 to extreme weather: fragility modelling, probabilistic impact assessment, and adaptation 485 measures. IEEE Trans. Power Syst. 32, 3747-3757 (2017) 486

61. Cadini, F., Agliardi, G.L., Zio, E.: A modeling and simulation framework for the reliabil- 487 ity/availability assessment of a power transmission grid subject to cascading failures under 488 extreme weather conditions. Appl. Energy. 185, 267-279 (2017) 489 


\section{Author's Proof}

Optimal Planning of Electric Power Systems

62. Cohen, S.M., Averyt, K., Macknick, J., Meldrum, J.: Modeling climate-water impacts on 490 electricity sector capacity expansion. In: ASME 2014 Power Conference. American Society 491 of Mechanical Engineers, pp. V002T10A007- V002T10A007 (2014)

63. Shao, C., Shahidehpour, M., Wang, X., Wang, X., Wang, B.: Integrated planning of electricity 493 and natural gas transportation systems for enhancing the power grid resilience. IEEE Trans. 494 Power Syst. 32(6), 4418-4429 (2017)

64. Ke, X., Di, W., Rice, J., Kintner-Meyer, M., Ning, L.: Quantifying impacts of heat waves on 496 power grid operation. Appl. Energy. 183, 504-512 (2016) 497

65. Liu, Y., Sioshansi, R., Conejo, A.J.: Multistage stochastic investment planning with multiscale 498 representation of uncertainties and decisions. IEEE Trans. Power Syst. 33(1), 781-791 (2018) 499

66. Shi, J., Oren, S.S.: Stochastic unit commitment with topology control recourse for power 500 systems with large-scale renewable integration. IEEE Trans. Power Syst. 33(3), 3315-3324 501 (2018)

67. Ershun, D., Zhang, N., Hodge, B.-M., Wang, Q., Lu, Z., Kang, C., Kroposki, B., Xia, Q.: 503 Operation of a high renewable penetrated power system with CSP plants: a look-ahead 504 stochastic unit commitment model. IEEE Trans. Power Syst. 34(1), 140-151 (2019) 505

68. Ben-Tal, A., Nemirovski, A.: Robust optimization-methodology and applications. Math. 506 Program. 92(3), 453-480 (2002) 507

69. Zeng, B., Zhao, L.: Solving two-stage robust optimization problems using a column-and- 508 constraint generation method. Oper. Res. Lett. 41(5), 457-461 (2013) 509

70. Ben-Tal, A., Goryashko, A., Guslitzer, E., Nemirovski, A.: Adjustable robust solutions of 510 uncertain linear programs. Math. Program. 99(2), 351-376 (2004) 511

71. Caunhye, A.M., Cardin, M.-A.: Towards more resilient integrated power grid capacity 512 expansion: a robust optimization approach with operational flexibility. Energy Econ. 72, 20-34 513 (2018)

72. Li, J., Li, Z., Liu, F., Ye, H., Zhang, X., Mei, S., Chang, N.: Robust coordinated transmis- 515 sion and generation expansion planning considering ramping requirements and construction 516 periods. IEEE Trans. Power Syst. 33(1), 268-280 (2018) 517

73. Ye, H., Li, Z.: Robust security-constrained unit commitment and dispatch with recourse cost 518 requirement. IEEE Trans. Power Syst, 31(5), 3527-3536 (2016) 519

74. Bertsimas, D., Litvinov, E., Sun, X.A., Zhao, J., Zheng, T.: Adaptive robust optimization for the 520 security constrained unit commitment problem. IEEE Trans. Power Syst. 28(1), 52-63 (2013) 521

75. Álvaro, L., Andy Sun, X., Litvinov, E., Zheng, T.: Multi-stage adaptive robust optimization for 522 the unit commitment problem. Oper. Res. 64(1), 32-51 (2016) 523

76. Lorca, A., Sun, X.A.: Multistage robust unit commitment with dynamic uncertainty sets and 524 energy storage. IEEE Trans. Power Syst. 32(3), 1678-1688 (2017) 